\title{
Sensitivity analysis to investigate the factors controlling the effectiveness of a nitrification inhibitor in the soil
}

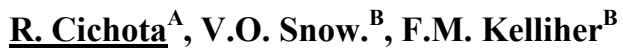 \\ ${ }^{A}$ AgResearch-Grasslands Research Centre, Private Bag 11008, Palmerston North 4442, New Zealand \\ ${ }^{B}$ AgResearch - Lincoln Research Centre, Private Bag 4749, Christchurch 8140, New Zealand \\ Email: rogerio.cichota@agresearch.co.nz
}

\begin{abstract}
Nitrification inhibitors have been proposed as an option to mitigate nitrogen (N) losses from farmland. One of these inhibitors, dicyandiamide (DCD), has been shown to significantly reduce $\mathrm{N}$ leaching and $\mathrm{N}_{2} \mathrm{O}$ emissions from nitrogen enriched soils with no adverse effects to the soil environment. However, the effectiveness of DCD in reducing $\mathrm{N}$ losses has been shown to be quite variable. We postulate this variability can be linked to the persistence of DCD in the soil layers where ammonium is located. DCD in soils will be subject to biodegradation and so the persistence of DCD in soils should be inversely proportional to microbial activity, for which temperature is a major driver. Furthermore, DCD is a neutralcharge compound and so should be highly mobile in soils and prone to leaching in direct proportion to rainfall. Thus, after application, the distribution of DCD in the soil profile over time can be affected by temperature, rainfall and the soil's drainage characteristics. We employed the simulation model APSIM with a recently-developed DCD module to analyse how the environmental conditions affect the processes governing the persistence of DCD in soils. The analyses involve data from simulations of typical pasture land in different locations across New Zealand with representative rainfall and temperature regimes and soil types. The simulations considered the application of DCD at different rates and in different seasons, over a 20 years period. Using sensitivity analysis techniques, we studied which processes play the greatest role in the disappearance of DCD. This led to recommendations for experimental protocols, including soil sampling, and data analysis which can be used to discern between leaching and degradation.
\end{abstract}

The persistence of DCD was studied using the solutes' apparent half-life, that is, the time taken for the concentration of the solute to decrease to half of its initial concentration. We use the adjective 'apparent' because the reduction in concentration is a result of a combination of degradation and leaching rather than degradation alone. The results from the simulations with DCD were compared with those from simulations with the application of an inert tracer in which the apparent half-life is affected by leaching alone. Differences in the apparent persistence of DCD and tracer from the soil's top $20 \mathrm{~cm}$ layer were used to infer the relative effects of degradation and leaching. The results showed large variability for the values of apparent half-life of both solutes, but the variability was considerably smaller for DCD than for the tracer. The month of application and location (weather) were the two major factors driving the variations in apparent half-life of both solutes, with soil-type and some of the interactions between factors being secondary. However the order of relevance for the factors was different for DCD than for the tracer. Overall the influence of month of application in the apparent half-life of DCD was quite small, whereas it was the most important factor for the disappearance of the tracer. The difference between the apparent half-lives of the two solutes can be used to infer the effect of degradation on DCD persistence; the results show, therefore, that the month of application is very important for determining DCD degradation. The relative effects of leaching and degradation follow a clear seasonal pattern, in summer degradation is the major factor and leaching is of lesser importance, but in winter leaching is much more important than degradation. This offset seasonality for the two processes results in the low overall seasonality for the apparent half-life of DCD. It also emphasizes the challenge of distinguishing the relative importance of leaching and degradation for DCD persistence in the soil. To better determine the causes of variation in residence time of DCD, and thus its effectiveness, experiments should use a tracer applied alongside DCD.

Keywords: $\quad$ Nitrogen losses, Water quality, Soil processes, DCD, Sensitivity analysis, APSIM simulation 


\section{INTRODUCTION}

Land use intensification has been a major trend in farming worldwide. In New Zealand, this trend is clearly reflected in the pastoral sector, which represents most of the managed land use in the country. The conversion of sheep and beef enterprises into dairy farms has increased considerably the area grazed by cattle and the number of animals per area has also increased. The number of dairy cows, for instance, has nearly doubled over the past 20 years (Clark et al., 2007; Statistics New Zealand, 2007). Also, the use of fertilizers on pastures has markedly increased as farmers search for ways to increase productivity (Clark et al., 2007; Monaghan et al., 2007). These changes resulted in increased amounts of nitrogen (N) being deposited onto the pastoral soils and consequently increasing $\mathrm{N}$ losses to the environment. Two main loss pathways for $\mathrm{N}$ which are of concern are leaching, which may result in the contamination of ground-water and waterways, and nitrous oxide $\left(\mathrm{N}_{2} \mathrm{O}\right)$ emissions, which is a powerful greenhouse gas and responsible for about $14 \%$ of New Zealand's total emissions (MFE, 2013). The major source for $\mathrm{N}$ losses in New Zealand are areas affected by urine deposited by grazing animals (Haynes and Williams, 1993; Monaghan et al., 2007). The use of dicyandiamide (DCD) as a nitrification inhibitor has been proposed as a technology for reducing $\mathrm{N}$ losses from grazed pastures. With the nitrification process inhibited, the conversion of $\mathrm{N}$ from ammonium $\left(\mathrm{NH}_{4}^{+}\right)$into highly mobile nitrate $\left(\mathrm{NO}_{3}^{-}\right)$form is slowed down considerably. Applications of DCD following urea deposition, either from fertilizers or urine, have been shown to reduce $\mathrm{N}$ losses, via leaching and gaseous emissions, and also enhance pasture productivity (Clough et al., 2007; Di et al., 2007; Moir et al., 2007). The use of DCD is recognized as a valid mitigation strategy and is accounted for in New Zealand's greenhouse gas inventory for the United Nations Framework Convention on Climate Change (Clough et al., 2007; MFE, 2013).

Although the ability of DCD to slow down nitrification has been demonstrated in several studies (e.g. Di et al., 2007; Singh et al., 2009; Welten et al., 2013), the effectiveness of DCD in reducing N losses in the field has been shown to be quite variable. The reasons for this variability are not well understood, but seem to be linked to the persistence of DCD in the soil layers where ammonium is located. This persistence is governed by speed of biochemical degradation of DCD as well as its transport down the soil profile via leaching. In the soil, DCD will be subject to biodegradation and so DCD persistence is related to microbial activity, for which temperature is a major driver (Kelliher et al., 2008). DCD is also a neutral-charge compound and potentially mobile in soils; it has been shown in various studies to be prone to leaching (e.g. Vogeler et al., 2007; Welten et al., 2013). Thus, after application, the distribution of DCD in the soil profile over time can be affected by the environmental conditions, especially temperature and rainfall, as well as the drainage characteristics of the soil.

Whether the use of DCD is aimed at reducing leaching for compliance with water quality regulation or reducing $\mathrm{N}_{2} \mathrm{O}$ emissions for greenhouse gas accounting purposes, we require simple but robust models that can predict DCD effectiveness in different environmental conditions. A robust model requires, therefore, a quantitative separation of the two processes, degradation and leaching, affecting its persistence in the soil. Only in this way the experimental results, which are inevitably limited, can be extrapolated to a wider range of environmental and management conditions. Unfortunately, at present, most of the existing experimental data report only the overall or apparent half-life. This makes it difficult, or impossible, to differentiate the relative effect of the major driving processes; a knowledge required for developing that simple yet robust model. An alternative approach is to use a process-based model for trying to de-convolve those competing processes. The objective of this work was to evaluate, via a modelling experiment, how the environmental conditions affect the processes governing the persistence of DCD in the soil. We employed sensitivity analysis techniques on a recently developed DCD module for the APSIM framework to study which process played the greatest role in the disappearance of DCD, and whether (or how) experimental data can be used to discern between leaching and degradation.

\section{METHODOLOGY}

\subsection{ASPIM and the DCD module}

The APSIM modeling framework (Keating et al., 2003; Holzworth et al., 2010), version 7.5 (r3087), was used in this work. The main modules included in the simulations were SWIM2 (Verburg et al., 1996) for describing soil water and solute movement, $\mathrm{AgPasture}(\mathrm{Li}$ et al., 2011) for pasture growth and $\mathrm{N}$ uptake, SurfaceOM (Probert et al., 2005) for decomposition of surface organic residues, and SoilN2 (Probert et al., 1998) for $\mathrm{C}$ and $\mathrm{N}$ transformations in the soil. The simulations also included manager scripts controlling grazing rotation and the application of two solutes, tracer and DCD. The solutes were simulated using the Solute2 module. For describing the tracer, Solute2 was parameterized as a non-reactive mobile solute; DCD 
was also set as a mobile solute but the functions describing its biochemical degradation were enabled. The degradation of DCD followed a first order decay function, with a rate of 0.1 (i.e. $10 \%$ per day) at optimum conditions. This was further affected by soil moisture, temperature, and organic matter content. The functions were parameterized based on published data (Williamson et al., 1996; Di and Cameron, 2004; Singh et al., 2008) following description similar to that given by Cichota et al. (2010).

\subsection{Simulation setup}

All simulations were a variant of a base simulation, where tracer and DCD contents in the soil's top $200 \mathrm{~mm}$ were monitored over a one year period. The simulations described a ryegrass/white clover pasture which was harvested every 21 days down to a residual biomass of $1500 \mathrm{~kg}$ dry matter (DM) per ha, and received monthly applications of $10 \mathrm{~kg} \mathrm{~N} \mathrm{ha}^{-1}$ as urea fertilizer, except in June and July. Both solutes, DCD and tracer, were applied together on the soil's surface at the recommended rate for DCD of $10 \mathrm{~kg} \mathrm{ha}^{-1}$.

The base simulation was modified by changing the soil type, the location of the weather data, and the timing of the application of the solutes. Four different generic soils (Table 1) and four weather data locations (Table 2) were used. Furthermore, for the driest site, Lincoln, the simulations were run with and without irrigation (irrigation season between October and April). The date for the solutes' application was defined as the $15^{\text {th }}$ day of February, April, June, August, or October, for every year between 1990 and 2010. Each combination of soil type, weather location and date of solutes' application was run as a separate simulation.

The soil descriptions were adapted from average data in the New Zealand National Soil Database (Wilde, 2003), and pedo-transfer functions were used to obtain the soil hydraulic characteristic curves (Cichota et al., 2013). The weather data was obtained from the Virtual Climate Station database (Tait et al., 2006).

The reduction over time of the amount of both tracer and DCD from the soil's top $200 \mathrm{~mm}$ was recorded for analysis.

Table 1. Basic properties of soils used in the simulations (top $20 \mathrm{~cm}$ ).

\begin{tabular}{|lcccccc|}
\hline Soil type & $\begin{array}{c}\text { Bulk } \\
\text { density } \\
\left(\mathrm{Mg} \mathrm{m}^{-3}\right)\end{array}$ & $\begin{array}{c}\text { Total } \\
\text { porosity } \\
\left(\mathrm{m}^{3} \mathrm{~m}^{-3}\right)\end{array}$ & $\begin{array}{c}\text { Sat. hydraulic } \\
\text { conductivity } \\
\left(\mathrm{cm} \mathrm{h}^{-1}\right)\end{array}$ & $\begin{array}{c}\text { Organic } \\
\text { carbon }(\%)\end{array}$ & $\begin{array}{c}\text { Sand } \\
(\%)\end{array}$ & $\begin{array}{c}\text { Clay } \\
(\%)\end{array}$ \\
\hline Clayey & 947 & 0.57 & 5.8 & 6.00 & 20 & 51 \\
Silt loam & 1039 & 0.53 & 52.6 & 5.20 & 21 & 15 \\
Sandy loam & 1134 & 0.49 & 71.7 & 4.00 & 64 & 9 \\
Sand & 1263 & 0.45 & 87.3 & 2.00 & 92 & 3 \\
\hline
\end{tabular}

Table 2. Locations for weather data and some basic characteristics.

\begin{tabular}{|lccc|}
\hline Location & Coordinates & $\begin{array}{c}\text { Annual rainfall } \\
(\mathrm{mm})\end{array}$ & $\begin{array}{c}\text { Average air temperature }\left({ }^{\circ} \mathrm{C}\right) \\
\text { annual }(\text { winter/summer })\end{array}$ \\
\hline Ruakura & $37.8 \mathrm{~S}, 175.3 \mathrm{E}$ & 1165 & $13.9(8.9 / 18.8)$ \\
Grasslands & $40.4 \mathrm{~S}, 175.6 \mathrm{E}$ & 993 & $13.1(8.4 / 17.8)$ \\
Lincoln $^{\mathrm{A}}$ & $43.6 \mathrm{~S}, 172.5 \mathrm{E}$ & 634 & $11.8(6.4 / 17.2)$ \\
Invermay & $45.9 \mathrm{~S}, 170.4 \mathrm{E}$ & 733 & $10.6(5.9 / 15.3)$ \\
\hline
\end{tabular}

${ }^{\mathrm{A}}$ Location used with and without irrigation

\subsection{Analyses}

Analyses were done on the temporal pattern of tracer and DCD disappearance from the top $200 \mathrm{~mm}$ of soil. In particular for this work, the time for the solutes to reach half of their initial concentration, termed apparent half-life (given in days), was used. As both solutes had the same leaching characteristics, the difference in the pattern of disappearance can be associated with the degradation of DCD. The analyses of the relative effect of DCD degradation were done using the ratio between the half-life of DCD and that of the tracer. The relevance of degradation for the disappearance of DCD from the soil decreases as the ratio between the halflife of both solutes approaches one. The values of the apparent half-life for each solute, as well as their ratio, was submitted to an analysis of variance and then to sensitivity analysis. The major driving factors analyzed for this work were the weather location, soil type, and month of solute application. The year of simulation was generally assumed to be part of the random variation.

The sensitivity index was defined as the percentage of the total variance explained by the variation of the major driving factors, as well as their interaction (Saltelli, 2002). All analyses were done using the $\mathrm{R}$ statistical package (R Core Team, 2013). 


\section{RESULTS}

The values for the apparent half-life simulated by APSIM were highly variable for both solutes (Figure 1). The variation was larger for the tracer than was for DCD, which reflects the fact it stayed in the soil for much longer, as it was not subject to degradation. The results also showed smaller variation for the two locations in the North Island (Ruakura and Grasslands) and for the autumn and winter months. There was a clear seasonal effect on the apparent half-life of the tracer, but this seasonality was not as defined for DCD. The soil type was also only a driving factor for the variations in the half-life of tracer, whereas the apparent halflife of DCD showed no considerable differences among different soil types.
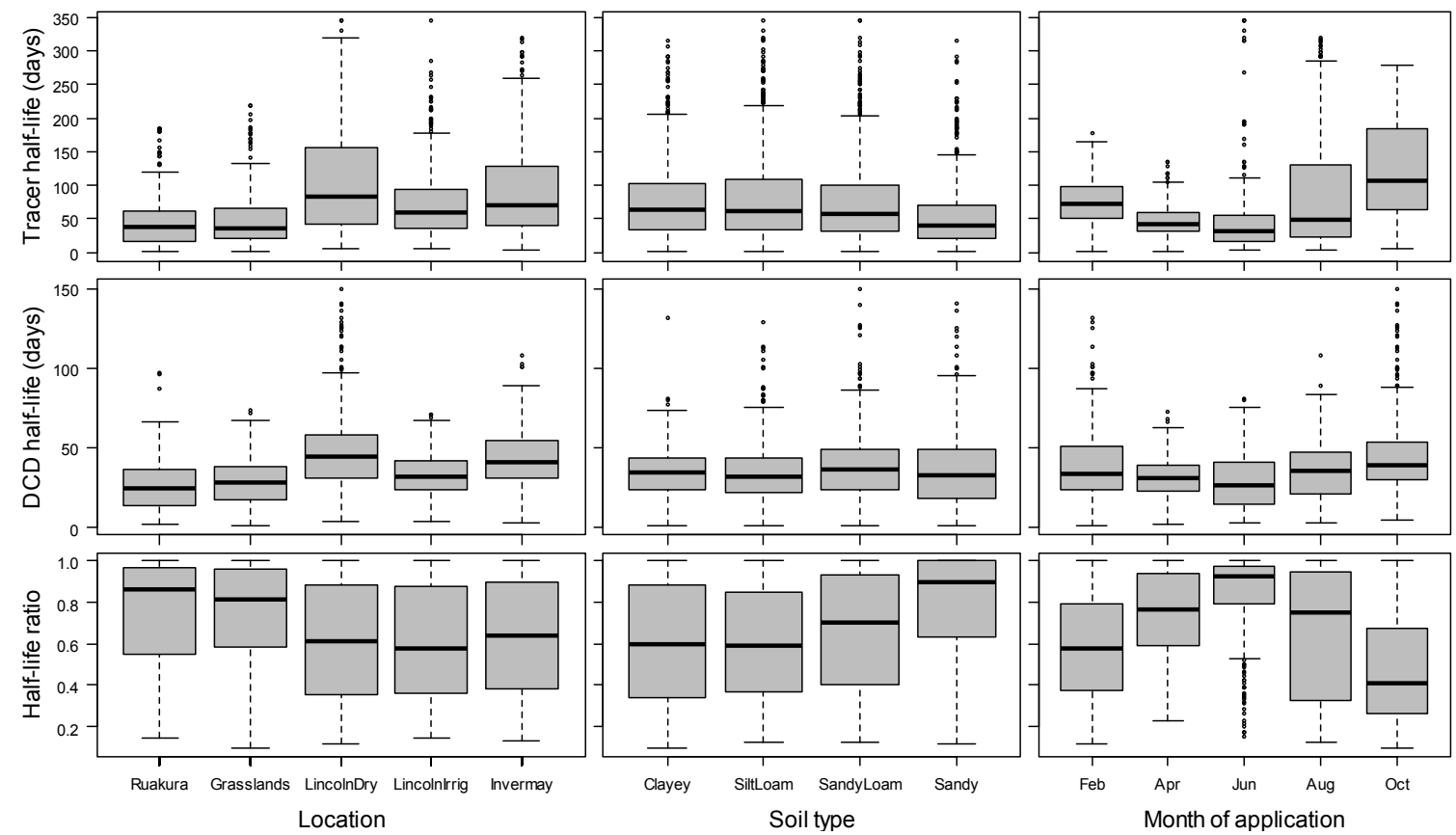

Figure 1. Variation of values for the apparent half-life for the tracer solute (upper row) and DCD (middle row) as function of weather location, soil type and month of solute's application. Lower row shows the variation of the ratio between the half-life of DCD and tracer.

The ratio between the half-life of DCD and tracer, when analyzed by soil type or month of application, showed variation patterns as expected. The ratio is close to unity, indicating a small effect of degradation, for the sandy soil or for the winter months. The analyses by location showed that the ratio between the halflife of DCD and tracer is considerably variable, but with a clear differentiation between the sites in the North and South Island. The simulations showed that DCD degradation was of limited importance for the two North Island sites.

The variations seen in Figure 1 were corroborated by the results of the sensitivity analysis. For both solutes, the month of application and the location were the most important factors influencing the apparent half-life of the solutes (Figure 2). The interaction between month and location was also considerably important. However, the order of relevance for these factors was different for the two solutes. For DCD, the month of application, especially, was much less important in determining its apparent half-life in the soil than it was for tracer. The month of application was again very

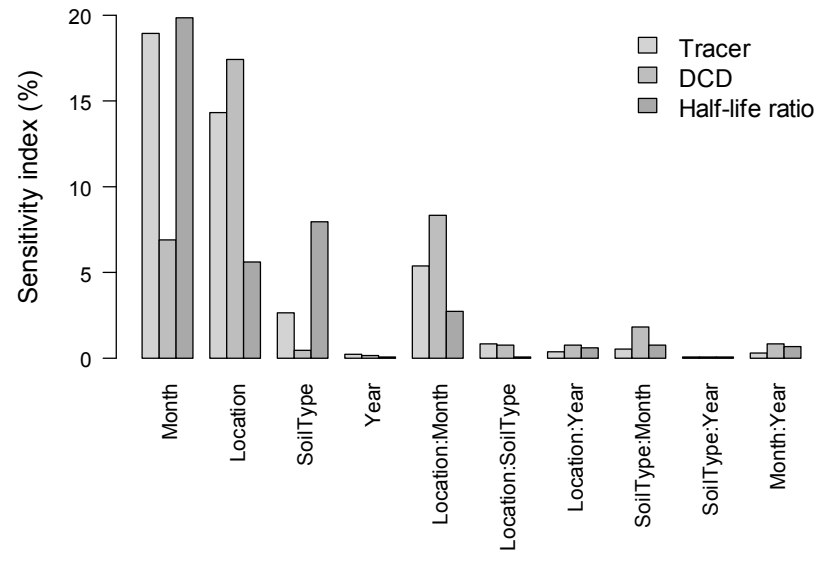

Figure 2. Results from the sensitivity analysis of the apparent half-life of two solutes (tracer and DCD) in the soil's top $20 \mathrm{~cm}$ and the ratio between the half-life of DCD and tracer. Results shown are for each major factor and their first order interaction. 
Cichota et al., Investigating the factors controlling the effectiveness of a nitrification inhibitor in soil

important for determining the ratio between the half-life of both solutes, with sensitivity

indices considerably smaller for weather/location.

None of the other factors or interactions showed great influence on the apparent half-life of either solute. The soil type had some relevance for the tracer, while for DCD only the interaction between soil type and month of application had a noticeable impact (Figure 2). Given these results, it was interesting to verify that soil type was the second most influential factor for the ratio between the half-life of DCD and tracer. It is important to notice also that most of the variation in the solutes' half-life (56 \% for tracer and $62 \%$ for DCD) was not explained by the variations in the four drivers considered here, or their interactions. Weather parameters, such as daily rainfall, temperature etc., are factors that might explain these variations. The correlation between the values of half-life for the two solutes was relatively high $(\mathrm{r}=0.642)$, which implies a considerably large effect of leaching on the disappearance of DCD from the soil.

\section{DISCUSSION AND CONCLUSIONS}

Considering the range of soils and climates used in this modeling experiment, the large observed variability in the values for the solutes' apparent half-life was expected. The smaller variations for DCD were not initially expected, but can be explained by the fact that degradation accelerates the disappearance of the DCD from the soil, and this effect is proportionally greater at the time when transport processes are limited (especially over summer). This lack of sensitivity of apparent half-life to month of application is because in the warmer months there is less leaching and more degradation while in the cooler months the importance of the processes are reversed. The combination leads to an apparent reduced sensitivity to month of application and obscures the effects of the competing processes. These competing processes affecting the apparent halflife also explains the lesser effects of soil type or weather location (i.e. climate) on DCD apparent half-life compared to that of the tracer.

The ratio between the half-life of DCD and tracer was also highly variable. Values close to unity for the sandy soil or for the winter months indicate the conditions in which leaching is the process responsible for most of DCD disappearance from the soil. Interestingly, when analyzed by location there was a clear separation between the sites in South and North Islands, with both North Island locations, Ruakura and Grasslands, with expected values for the ratio between half-lives considerable higher than the southern counterparts. This goes against the common assumption that the generally lower efficiency of DCD in the North Island soils was due to higher degradation rates. It seems that higher rainfall amounts and perhaps the rainfall pattern favor DCD leaching to a larger extent than previously thought.

The leaching of solutes seems to play a large role in the disappearance of DCD from the soil's top layer. This was evidenced by the relatively large correlation between the half-life values for both DCD and the tracer. Indeed, for the situation where leaching was favorable (that is: autumn/winter months, or sandy soil, or years with rainfall higher than average), the difference between the half-life of both solutes was very small. Also the major drivers for defining the half-life of both solutes were the month of application and the weather location. However, the order of these drivers was not the same for the two solutes and there were differences in the way the drivers interact (Figure 2). The largest difference between the two solutes was with respect to the month of application. The sensitivity analysis corroborates the results shown in Figure 1, where the month of application seems to make little impact on the half-life of DCD. Because tracer is only removed via leaching, this implies that the degradation of DCD is especially affected by the month of application. This can be seen also from the results from the sensitivity analyses of the ratio between the halflife of DCD and tracer (Figure 2). The other driving factors were, in general, of less relevance, with the exception of soil type for the half-life ratio. However, it is interesting to notice that the differences in the sensitivity index were larger for the interactions involving the month of application. So, as month of application was the major driver defining the rate of leaching for tracer in the soil, the results indicate that degradation of DCD in the soil is only an important process if the transport through the soil is slow.

It does not seem to be possible therefore to easily separate the transport from the degradation processes when analyzing the data typically collected in experiments. To be really useful for the purposes of separating the two processes affecting apparent half-life of DCD the experimental data should contain coupled measurements of DCD remaining in the soil and leaching. There are many technical difficulties associated with measuring leaching so we would recommend that applying and measuring DCD alongside a tracer combined with regular soil sampling to determine the remaining amounts of the two solutes would be a useful experimental design to infer the relative importance of leaching and degradation of DCD and thus to develop best practices to extend DCD effectiveness in the soil. 
Cichota et al., Investigating the factors controlling the effectiveness of a nitrification inhibitor in soil

\section{ACKNOWLEDGEMENTS}

This work was supported by the Ministry for Science and Innovation through the programme "Dairy Systems for Environmental Protection".

\section{REFERENCES}

Cichota, R., Vogeler, I., Snow, V.O., Shepherd, M., 2010. Modelling the effect of a nitrification inhibitor on $\mathrm{N}$ leaching from grazed pastures. Proc. New Zeal. Grass. Assoc., 72, 43-47.

Cichota, R., Vogeler, I., Snow, V.O., Webb, T.H., 2013. Ensemble pedotransfer functions to derive hydraulic properties for New Zealand soils. Soil Res., 51, 94-111.

Clark, D.A., Caradus, J.R., Monaghan, R.M., Sharp, P., Thorrold, B.S., 2007. Issues and options for future dairy farming in New Zealand. New Zeal. J. Agr. Res., 50, 203-221.

Clough, T.J., Di, H.J., Cameron, K.C., Sherlock, R.R., Metherell, A.K., Clark, H., Rys, G., 2007. Accounting for the utilization of a $\mathrm{N}_{2} \mathrm{O}$ mitigation tool in the IPCC inventory methodology for agricultural soils. Nutr. Cycl. Agroecosyst., 78, 1-14.

Di, H.J., Cameron, K.C., 2004. Effects of temperature and application rate of a nitrification inhibitor, dicyandiamide (DCD), on nitrification rate and microbial biomass in a grazed pasture soil. Aust. J. Soil Res., 42, 927-932.

Di, H.J., Cameron, K.C., Sherlock, R.R., 2007. Comparison of the effectiveness of a nitrification inhibitor, dicyandiamide, in reducing nitrous oxide emissions in four different soils under different climatic and management conditions. Soil Use Manage., 23, 1-9.

Haynes, R.J., Williams, P.H., 1993. Nutrient cycling and soil fertility in the grazed pasture ecosystem. $A d v$. Agron., 49, 119-199.

Holzworth, D.P., Huth, N.I., de Voil, P.G., 2010. Simplifying environmental model reuse. Environ. Model. Softw., 25, 269-275.

Keating, B.A., Carberry, P.S., Hammer, G.L., Probert, M.E., Robertson, M.J., Holzworth, D., Huth, N.I., Hargreaves, J.N.G., Meinke, H., Hochman, Z., McLean, G., Verburg, K., Snow, V., Dimes, J.P., Silburn, M., Wang, E., Brown, S., Bristow, K.L., Asseng, S., Chapman, S., McCown, R.L., Freebairn, D.M., Smith, C.J., 2003. An overview of APSIM, a model designed for farming systems simulation. Eur. J. Agron., 18, 267-288.

Kelliher, F.M., Clough, T.J., Clark, H., Rys, G., Sedcole, J.R., 2008. The temperature dependence of dicyandiamide (DCD) degradation in soils: A data synthesis. Soil Biol. Biochem., 40, 1878-1882.

Li, F.Y., Snow, V.O., Holzworth, D.P., 2011. Modelling seasonal and geographical pattern of pasture production in New Zealand. New Zeal. J. Agr. Res., 54, 331-352.

MFE, 2013. New Zealand's greenhouse gas inventory - 1990-2011. Ministry for the Environment, Wellington, New Zealand, p. 424.

Moir, J.L., Cameron, K.C., Di, H.J., 2007. Effects of the nitrification inhibitor dicyandiamide on soil mineral $\mathrm{N}$, pasture yield, nutrient uptake and pasture quality in a grazed pasture system. Soil Use Manage., 23, 111-120.

Monaghan, R.M., Hedley, M.J., Di, H.J., McDowell, R.W., Cameron, K.C., Ledgard, S.F., 2007. Nutrient management in New Zealand pastures - recent developments and future issues. New Zeal. J. Agr. Res., 50, 181-201.

Probert, M.E., Delve, R.J., Kimani, S.K., Dimes, J.P., 2005. Modelling nitrogen mineralization from manures: Representing quality aspects by varying C:N ratio of sub-pools. Soil Biol. Biochem., 37 , 279-287.

Probert, M.E., Dimes, J.P., Keating, B.A., Dalal, R.C., Strong, W.M., 1998. APSIM's water and nitrogen modules and simulation of the dynamics of water and nitrogen in fallow systems. Agr. Syst., 56, 128.

R Core Team, 2013. A language and environment for statistical computing. R Foundation for Statistical Computing, Vienna, Austria. 
Cichota et al., Investigating the factors controlling the effectiveness of a nitrification inhibitor in soil

Saltelli, A., 2002. Sensitivity analysis for importance assessment. Risk Analysis, 22, 579-590.

Singh, J., Saggar, S., Bolan, N.S., 2009. Influence of dicyandiamide on nitrogen transformation and losses in cow-urine-amended soil cores from grazed pasture. Anim. Prod. Sci., 49, 253-261.

Singh, J., Saggar, S., Giltrap, D.L., Bolan, N.S., 2008. Decomposition of dicyandiamide (DCD) in three contrasting soils and its effect on nitrous oxide emission, soil respiratory activity, and microbial biomass - An incubation study. Aust. J. Soil Res., 46, 517-525.

Statistics New Zealand, 2007. Agriculture in New Zealand. Analytical Reports, Wellington, pp. Downloaded in 24/09/2007 (http://www.stats.govt.nz/analytical-reports/agriculture-in-nz/default.htm).

Tait, A., Henderson, R., Turner, R., Zheng, X.G., 2006. Thin plate smoothing spline interpolation of daily rainfall for New Zealand using a climatological rainfall surface. Int. J. Climatol., 26, 2097-2115.

Verburg, K., Ross, P.J., Bristow, K.L., 1996. SWIMv2.1 User Manual. Divisional Report No 130. www.apsim.info/wiki/public/Attachments/Module-Documentation/SWIMv21UserManual.pdf. CSIRO Division of Soils, Canberra, Australia.

Vogeler, I., Blard, A., Bolan, N., 2007. Modelling DCD effect on nitrate leaching under controlled conditions. Aust. J. Soil Res., 45, 310-317.

Welten, B.G., Ledgard, S.F., Schipper, L.A., Judge, A.A., 2013. Effect of amending cattle urine with dicyandiamide on soil nitrogen dynamics and leaching of urinary-nitrogen. Agr. Ecosyst. Environ., $167,12-22$.

Wilde, R.H., 2003. Manual for National Soils Database. Landcare Research, Palmerston North, p. 53.

Williamson, J.C., Menneer, J.C., Torrens, R.S., 1996. Impact of dicyandiamide on the internal nitrogen cycle of a volcanic, silt loam soil receiving effluent. Appl. Soil Ecol., 4, 39-48. 